\title{
The effect of temperature on a mono-crystalline solar PV panel
}

\begin{abstract}
There are three important parameters in solar photovoltaic (PV) panel performance, namely maximum output power, short-circuit current, and open-circuit voltage. All these parameters are affected by temperature fluctuations. This research is focused on the behaviour of a mono-crystalline solar PV panel under different temperatures using experimental work and the results are validated with a corresponding simulation using Matlab/Simulink software. The experimental and simulation results show that the electrical parameters change with a variation in temperature. When the temperature rises, the maximum output power and the open-circuit voltage decrease while the short-circuit current increases. Typically, when the surface temperature of the solar PV panel increases, the efficiency of the solar PV panel reduces.
\end{abstract}

Keyword: Mono-crystalline; Solar PV panel; Temperature 